\title{
Case Study: Program Management of Volume Modules
}

\author{
Gregory F. Starzyk \\ Associate Professor, Department of Construction Management \\ California Polytechnic State University, San Luis Obispo, CA, USA \\ "Corresponding author's e-mail: gfstarzyk@calpoly.edu
}

\begin{abstract}
Volume module systems in the refining and petrochemical industries are large, multi-level systems that are fabricated offsite and stacked onsite, with integral piping and wiring interconnections. This is a case study in a program management system that was introduced for a particular volume module system. Modular design and fabrication suffer from inherent shortcomings: it is neither cheap nor fast nor does it result in any meaningful increase in quality. Lessons learned reveal cheaper, faster and better methods that overcome the inherent shortcomings of modular design and construction. These lessons can inform current trends in modular design and fabrication in the USA and Canada.
\end{abstract}

\section{KEYWORDS}

Volume module design; Volume module fabrication; Program management

\section{AUTHORITIES}

The modular work being investigated in this case study had been undertaken by the Universal Oil Products Co., now simply UOP, a multinational research and engineering company. The study's author, Gregory Francis Starzyk, a 23-year veteran employee of UOP, writes from direct experience. Starting out in UOP's construction management group and later its modular systems group, his professional experiences include that of design engineer, construction manager, project manager, product development manager, business manager of the Recovery Plus system and global planner. The modular projects under his purview are in operation on six continents.

\section{INTRODUCTION}

UOP provides processes, products and management services to oil refiners and petrochemical processors worldwide. UOP has been a privately-held company: a think tank of the major oil companies; and a division of Signal Oil Co., Allied Chemical, Allied-Signal, Dow Chemical, Union Carbide Corporation, and today, a wholly-owned subsidiary of Honeywell, Inc. Based in Des Plaines, Illinois, UOP has been granted over 25,000 patents worldwide in its 105-year history (Remsberg \& Higdon, 1994, p.430). It is far and away the leading provider of oil refining and petrochemical processes. One cannot buy gasoline anywhere on the planet without paying a royalty to UOP. It employs over 3,500 people worldwide, nearly $800 \mathrm{PhD}$ researchers, 1,500 engineers, and a small cadre of construction managers (Remsberg \& Higdon, 1994, p. 430). 
A utility patent provides its owner with the right to a limited-duration legal monopoly on its invention (Merges, et al., 2007, p.127). But this right comes at the expense of disclosing patented knowledge to the public (Meges, et al., 2007, p.127). Rarely, however, can an invention be successfully knocked-off solely from the information disclosed in its patent. Much of what makes an invention viable arises from trade secrets. Trade secrets are also protected under intellectual property laws. But trade secret protection is unlike patent protection. Once a trade secret is disclosed, it is no longer protectable. Even when a disclosure is through theft or in breach of a non-disclosure agreement, it is no longer protectable, once disclosed. The discloser can be enjoined against further disclosures but the courts cannot disgorge knowledge from the public discourse. A trade secret becomes public knowledge upon its disclosure.

In the early 80s, UOP formed a modular systems group for the purpose of trade secret protection. They began by partnering with other firms to design and fabricate modules for UOP's clients. By the late 80s, UOP's growing modular business was engaging purposes other than trade secret protection. In time, their modular projects competed against conventional, site-built construction projects. To date, more than 1,400 fully-engineered and pre-fabricated modular process units have been delivered to UOP's customers around the world (Modular Refining Units, n.d.). The Recovery Plus System was introduced in 1986 (CCR, n.d.). Program management of the Recovery Plus system is the particular focus of this case study.

\section{FALLACIES OF MODULAR CONSTRUCTION}

Modular construction suffers from intrinsic shortcomings. It is neither cheap nor fast nor does it result in any meaningful increase in quality. With conventional construction, most of the smallbore piping, cable or conduit is field routed. But every piece of pipe, cable or conduit must be pre-designed before attachments to a module. There are also far more connections. The consequences are that more detailed design and fabrication work is required and this not only costs more but it adversely impacts schedules. It simply costs more and takes longer to begin fabricating modules in a shop than it takes to get started with conventional field construction.

Steel frames for modules are generally more robust than site-built frames. The steel frame for a module must be designed not just for seismic and wind loads but for transportation loads. Typically, transportation loads control the design. This adds steel to modular construction in excess of that required for conventional construction.

Perhaps the most misunderstood shortcoming of volume module construction is that small tolerances, projected over large distances, create misfits. The dimensional tolerances in the manufacturing of structural steel and piping confound a fabricator's ability to accurately align the connections of steel and piping of a large volume module. Invariably, fabricators elect to fabricate adjacent modules together, aligning connections in the shop, before disassembling them to ship to the site. In its effect, modules are assembled twice: once in the shop for fit up and then once again in the field. This double-assembly adversely impacts cost and schedule.

Quality is not improved in meaningful ways. The quality that customers expect is safe operation that meets performance guarantees. Anything less than that standard is unacceptable. Anything more than that standard is of no consequence. Chemical processes don't perform better or more 
safely just because the plant happened to be fabricated indoors in a shop. So, while it could be claimed (and often is claimed) that higher quality arises under the controlled conditions of a shop, this type of quality improvement is of no consequence to the customer.

\section{RECOVERY PLUS PRODUCT DEVELOPMENT}

UOP executive management resolved to penetrate its Recovery Plus market as quickly as possible. To the modular systems group, however, hiring an army of project managers to direct those projects was a non-starter. A development project was commenced to design a fast and efficient project delivery methodology. Project development efforts began on a number of different fronts: simplifying the design process; standardizing equipment; partnering with a refrigeration compressor manufacturer; and partnering with a refrigeration system fabricator.

\section{Simplifying the Design Process}

BIM did not exist when the Recovery Plus program was developed. But with a BIM-like vision of the future, automation of the design drawing process was attempted. The technology of the time did not support that effort, however. It was soon realized that the existing design process was wasteful. Automating a wasteful process would only guarantee a permanently wasteful process. Instead, processes were changed.

For every UOP process license, engineers provide schematic and design development documents. Detailed design - a refinery detailed design package is equivalent to a commercial construction documents package - is handed off to engineering contractors. The schematic/design development package is called a "Schedule A," a term invented by UOP. For a process guarantee to apply, detailed designs must conform to UOP's Schedule A deliverables: specifications for major equipment and instruments and a Piping and Instrument Diagram (P\&ID).

UOP's P\&ID is a simplified version of the P\&ID of engineering contractors. UOP would draw its P\&ID; there would be a rigorous, internal review; the engineering contractor would redraw UOP's P\&ID, adding additional layers of detail; then UOP would review the engineering contractor's P\&ID for conformance with UOP's P\&ID. A period of revision, re-review and approval would follow. Only then could detailed design commence. Studies suggested that $60 \%$ of the total manhours required to produce a conformed P\&ID were consumed doing non-valueadded work. Eliminating that work reduced costs and shortened schedules. The solution was a partnering agreement with an engineering/fabrication contractor. This contractor drew the first instance of UOP's P\&ID. Afterward, a normal P\&ID review was performed. UOP engineers resisted this process change at first. But their resistance subsided after the first few projects. Process performance and safety were not compromised and the additional details on the P\&ID did not hinder UOP's ability to conduct its P\&ID check.

\section{Standardizing Equipment}

As with all hydrocarbon processes, a variety of pumps, exchangers and vessels are required. Every oil refinery and petrochemical plant processes a different slate of crude oil, through different types of unit operations to produce different product streams that are blended in various ways to serve different markets. Accordingly, every pump, exchanger and vessel in a process must be custom designed to satisfy the unique processing demands of each particular project. So, 
while the flow diagram of one Recovery Plus system might look exactly like that of the next, no two detailed designs are every alike. Designing a unique plant for every Recovery Plus system was, of course, the very thing that needed to change. Part of the eventual solution was the standardization of equipment configurations around critical dimensions.

Shell and tube heat exchangers consist of a long, metal cylinder, known as a shell, inside of which are mounted long, metal pipes, known as tubes. Heat energy from a fluid within the shell is exchanged with a different fluid flowing within the tubes. Caps mounted on the shell ends, known as heads, rout fluids through the shell and tubes. Various flow schemes are possible. Exchanger designers avail themselves of these various configurations, along with the sizing and material properties of the shell and tubes, to optimize performance and minimize cost.

Shell and tube heat exchangers are mounted at two points, known as saddles, that transfer loads to the structural steel. Fixing these locations, it was reasoned, would create a repeatable design. It was only necessary to specify fixed tube lengths and assume the maximum load possible with the largest shell diameter that a module could accommodate. The actual number of tubes, their size, and the resulting shell diameter could vary. Presuming high, fixed loads at invariable locations would result in a less than optimum exchanger design and an excess of steel in the structure, but the structural design itself would not have to be completely redone for each project. Far more cost was saved by reducing or eliminating structural design engineering manhours across multiple projects than could ever be spent on extra metal.

UOP's designers struggled with this concept, at first. But in time, they became comfortable with designing exchangers that fully met performance specifications but that did not necessarily represent the most economical exchanger design. The same idea was applied to horizontal vessels. Lengths were fixed but diameters were allowed to vary. This was far less problematic for the vessel designer because vessel volume was often the only controlling parameter.

Pumps were restricted to a particular type, sole-sourced from a particular supplier. Sole-sourcing is problematic with purchasing agents, who favor competitive bidding. Provided with justification, however, they cautiously cooperated. A requirements contract was envisioned. A requirements contract is obtained through competitive bidding on a horizontal purchasing agreement stipulating the meeting of all requirements over a stipulated time period. Both favorable pricing and predictability were achieved through this means.

\section{Partnering with a Refrigeration Compressor Manufacturer}

Chilling of process streams for the Recovery Plus system required refrigeration. A flooded screw compressor is very well suited for the specified refrigeration duties and temperatures required by the system. Flooded screw compressors are far more economical and trouble-free than any alternative. Although the flooded screw was the right technical solution, this solution was not well received by customers. They did not so much disagree with the suitability of the application, but reluctant to adopt it from a lack of familiarity with the equipment. Few, if any, refiners or petrochemical processors had any standards in place for flooded screw compressor equipment.

A flooded screw compressor is unusual in that a lubricating oil is injected into the inlet of the compressor. Liquids are anathema to most compressors. Heating and rapid vaporization of 
liquids can cause catastrophic damage. Usually, liquids are carefully removed from inlet streams so as to avoid such failures. However, flooded screw compressors are intentionally designed for lube oil injection. Lube oil liquid is centripetally thrust to the outside of the compressor screws where it seals the gap between the screws and the compressor casing. This gap sealing enables the gases to be compressed in the cavities between the rotating screws. This scheme results in much lower compressor operating temperatures, increasing the efficiency of compression and the durability of the compressor. Liquid-induced failures are virtually non-existent.

The lubricating oil stays mixed with the compressed gases in the compressor's outlet. This lube oil must be removed prior to downstream processing. Removal is accomplished by a highefficiency, multi-stage lube oil separation system that recirculates the lube oil back to the compressor's inlet. Despite that a flooded screw compressor is of no use without a lube oil separation system, not a single flooded screw compressor manufacturer fabricates its own lube oil separation systems. Rather, they sell their compressors to licensed suppliers of industrial refrigeration systems. These suppliers then design and fabricate the separator systems, yielding an integrated compressor/separator package. This compressor/separator package is then incorporated into the supplier's industrial refrigeration systems.

The ability of UOP to provide price quotes to its clients was hampered by an inability to size the compressor. Not only was UOP unable to size the compressor but it lacked the resources to do its own detailed design and fabrication. To size the compressor and develop a price for the system it was necessary to partner with a willing industrial refrigeration supplier. But capable suppliers were neither experienced nor particularly enthusiastic about supplying refrigeration systems to meet the stringent specifications typical of the modern oil refinery or petrochemical plant. Establishing even ballpark budget pricing was often a frustrating and time-consuming process.

The flooded compressor manufacturers, when approached, where polite but unwilling to work directly with UOP. In time, however, Lewis Energy Systems of Salt Lake City, USA was chosen to be their preferred system fabricator. After that occurred, our favored compressor manufacturer, Mayekawa Corp. through their U.S. subsidiary, Mycom USA, initiated conversations that led to a very productive partnering between the three companies. What had not been appreciated, at first, was Mycom's protective relationships with their licensed fabricators. Once Mycom's relationship with Lewis Energy was secured under our preferred supplier relationship with Lewis Energy, constructive conversations began. With Mycom's cooperation and advice potential clients could be provided with near instant budget price quotations and firm-fixed-price proposals within a few days.

\section{Partnering with a Refrigeration System Fabricator.}

Commercial coolers and flash freezers are common applications for flooded screw compressor refrigeration systems. Refrigeration system fabricators are very familiar with these applications. Refinery and petrochemical plants are different in ways that have very significant cost consequences. Refrigeration system fabricators tend to lack familiarity with these applications.

Commercial coolers and flash freezers are designed for economy and with minimal footprints. Refiners and petrochemical processors subordinate economy to safety and will not compromise on process performance. A plant that does not perform is a failure at any cost. Refiners and 
petrochemical processors are skeptical of small footprints too. They want a large enough footprint to facilitate maintenance and inspection access to all instruments and equipment in order to assure safety and continuous process performance.

The extensive and expensive instruments and controls demanded by refiners and petrochemical plants far exceed the minimal and inexpensive instrumentation expected with a commercial cooler or flash freezer. Refiners and petrochemical plants control processes with complex and expensive distributed control systems. Commercial coolers and flash freezers are controlled by simple and inexpensive, locally mounted microprocessors.

Refinery and petrochemical equipment are installed outdoors. They are continually exposed to the elements and require corrosion-protective coatings. They are expected to operate $24 \times 7$, without interruption, with minimal process heat loss. Passive fire protection of structural steel is mandatory. Commercial coolers and flash-freezers may or may not be exposed to the weather and heat loss and corrosion protection is variable. They are sometimes spared or used intermittently. Passive fire protection is rarely provided.

The refrigerant of choice with refiners is propane and the process fluid of the Recovery Plus system is mostly hydrogen. These are volatile gases. Petrochemical plants prefer ammonia as a refrigerant. It is toxic in high concentrations. An explosion in a refinery or petrochemical plant or an ammonia release in a petrochemical plant may have catastrophic consequences with potential for injury and loss of life. A broken cooler or flash freezer is just a nuisance.

A short list of potential flooded screw compressor fabricators was developed. They were invited to bid three hypothetical systems. After analysis, the offering of Lewis Energy Systems of Salt Lake City rose to the top. Lewis Energy distinguished themselves by their willingness to meet the stringent requirements of UOPs refinery and petrochemical clients.

UOP chose Lewis Energy to be its preferred supplier for both refrigeration and process modules of the Recovery Plus system, in the Americas. Their scope included detailed design drawings for the refrigeration modules. In time, the first instance of UOP's P\&ID, all detailed design work for both the process and refrigeration modules, and fabrication of both process and refrigeration modules was subcontracted to Lewis Energy. Modular projects in Europe and North Africa were managed by UOP's Antwerp, Belgium office. Antwerp managers thought differently about outsourcing detailed design. In time they implemented a novel solution: they leveraged Fabricom, N.V., a subsidiary of a partner as a fabricator for all process and refrigeration modules; obtained a schematic design for the refrigeration system from the Quiry Group, France, another subsidiary of the same partner; and performed all detailed design in house. Mayekawa was aligned with Quiry. Modular projects in Japan were managed by UOP's Tokyo-Shinigawa office. They established a third variant. All design and fabrication were subcontracted to Chiyoda whom had a continuing business relationship with Mayekawa.

In the end, there were sole-suppliers for all design and fabrication. UOP Tokyo-Shinigawa managed projects sold to clients in Japan; UOP Antwerp, Belgium managed projects sold to European and North African clients; UOP North America/Lewis Energy managed projects sold to clients in North America and everywhere else outside of Europe, North Africa and Japan. 


\section{LESSONS LEARNED}

Each commercial building sector will address the same functional uses but with different and unique designs, and specifying equipment and systems that respond to that unique design. Likewise, each Recovery Plus will address the same process functions but with different and unique designs, and specifying equipment and systems that respond to that unique design. The volume modules scheme of the Recovery Plus System is profitable vis-à-vis traditional design and construction. It all began with the intent to build fast and many. It evolved into a program management system. The benefits of program management systems are relevant still today. The lessons learned are applicable to any entity contemplating a modular or offsite fabrication program.

Presuming competition against site-built construction, UOP's modular clients were always told that their modules, when installed, would look just like site-built construction. Although that claim seemed innocuous, it proved costly to execute. The structural steel at the bottom of atgrade modules had to be extended for the steel to be covered with paving. Columns rising out of paving is the look of site-built construction. One doesn't know that they are walking onto a module when paving is level throughout the plant. But the extension added depth. Constrained by shipping limitations in its height and with added depth at its bottom, the remaining usable height limited the amount of equipment that could be installed on a module. Often, two stacked modules were required where one at-grade module would have sufficed had it not been for looking like site-built construction. Recovery Plus clients were interviewed. This revealed that clients put no value on "looking like site-built construction." They expected a module to look like a module. Stepping up into an installed module was acceptable to them. They did not understand why anyone would think otherwise.

The first new Recovery Plus system was sold to a refinery that required a different process configuration, a configuration that was substantially different from what was in the program. Although the project enabled testing of certain concepts, resources were waisted on developing unique, unrepeatable designs. A systems approach to design cannot serve all customers.

Everybody loves a challenge. Even if you know the solution in advance, it's better to ask your designers to find the solution then to tell them what your solution is. You may be surprised at what they come up with. It could be the solution that you knew was coming. It could be something different and better. There is no greater advocate for change than them who owns the change.

Designers and fabricators are contractually obligated to give you that for which they are contractually obligated. They are under no obligation to give you more than you contracted for. When "more" means an improvement that lessens their fee, they might not be willing to suggest that improvement. One of the better ways to incentivize improvement suggestions is to promise future work. But you must first be trusted to follow through on your promise if you are to get to the good stuff that reduces costs. And you have to trust them to not take advantage of the privilege of repeat work to jack up their fee. Trust is a two-way street in a productive partnership. But trust doesn't just happen by accident. It arises from one's actions. There comes a 
time during every project where you will want to hold your supplier's feet to the fire. It is force of habit. But with the right supplier, should you instead help them financially with their difficulties, you will begin to develop their trust. Costs will begin to disappear; unnecessary welding here, different cable routing there. Major improvements also appear. One of our biggest was a $\$ 1,500$ innovation that eliminated $\$ 150,000$ in instrumentation and controls, as unnecessary. In the end, the system became more competitively priced vis-à-vis a conventionally designed and constructed system.

Site built construction is an opportunity-driven business. It can be ramped up and throttled back to match demand. Modular fabrication is a capital-intensive business. One cannot easily ramp it up or throttle it down. Demand variability corrupts a capital-intensive business (Hopp \& Spearman, 2001). Depreciation and amortization continue regardless of demand. And demand for the Recovery Plus systems was lumpy. But Lewis Energy had other customers whose work filled their shop in the gaps between our lumpy sales. Were it not for that, the Recovery Plus program would have failed. Managing demand variability is the most challenging aspect of modular design and construction.

Our industry has a long tradition of designing and building anew; from a clean sheet of paper; invoking a large cast of companies; producing a bespoke final product. But when the same parties are engaged a second time does it not go faster, with fewer errors, and higher quality (Thomsen \& Sanders, 2011)? Personal experience teaches us that things get better with practice. Modular construction enables the same group of people to design and fabricate the same or similar components repeatedly. Repetition enables refinement of work. Acquired knowledge can be rotated into the program and retained. Reduction of rework is a major cost reduction opportunity. But cost reductions only arrive as the same people design and fabricate repeatedly. In the absence of continuity, the opportunity for knowledge acquisition is squandered.

\section{CONCLUSION}

Modular design and construction suffer from inherent shortcomings: it is neither cheap nor fast nor does it result in any meaningful increase in quality. Recovery Plus upset the status quo ante: clients were debriefed; customers picked; designers challenged; partners trusted; demand variability was managed; repetition, refinement and rotation ordained; and program management was established. Cheaper, faster and better methods were incorporated into a program that overcame the inherent shortcomings of modular design and construction.

\section{REFERENCES}

CCR. (n.d.). < https://www.uop.com/equipment/ccr-regeneration/\#recovery> (Jan. 26, 2019). Hopp, W.J. and Spearman, M.L. (2010). Factory Physics. (2 ${ }^{\text {nd }}$ ed.). New York: McGraw-Hill. Merges, R.P., Menell, P.S. \& Lemley, M.A. (2007). Intellectual Property in the New Technological Age. (revised $4^{\text {th }}$ ed.). Austin, Tx.: Wolters Kluwer Law \& Business.

Modular Refining Units. (n.d.). <https://www.uop.com/processing-solutions/refining/modularrefining-units/> (Jan. 26, 2019)

Remsberg C. and Higdon, H. (1994). Ideas for Rent: the UOP Story. Des Plaines, IL: UOP. Thomsen, C and Sanders, S. (2011). Program Management 2.0. McLean, VA: CMAA 